\title{
Function and clinical potential of microRNAs in hepatocellular carcinoma (Review)
}

\author{
LIJUAN WANG ${ }^{1}$, YONGFANG YUE $^{2}$, XIAN WANG ${ }^{2}$ and HONGCHUAN JIN ${ }^{2}$ \\ ${ }^{1}$ Department of Hematology, Hematology Laboratory, Linyi People's Hospital, Shandong University, Linyi, Shandong 276003; \\ ${ }^{2}$ Department of Medical Oncology, Institute of Clinical Science, Sir Run Run Shaw Hospital, \\ Medical School of Zhejiang University, Hangzhou, Zhejiang 310000, P.R. China
}

Received April 30, 2014; Accepted August 25, 2015

DOI: $10.3892 / \mathrm{ol} .2015 .3759$

\begin{abstract}
MicroRNAs (miRNAs) are small non-coding RNAs involved in the initiation and progression of several types of human cancer, including hepatocellular carcinoma (HCC), which is one of the most common types of cancer and the third leading cause of cancer-related mortality worldwide. Mounting evidence has demonstrated that miRNAs play a vital role in HCC, hepatitis, alcoholic liver disease, liver cell development and the metabolic functions of the liver. The aim of the present review was to summarize the most recent findings on the functions of miRNAs in the liver and discuss their potential roles in the diagnosis, prognosis and treatment of HCC.
\end{abstract}

\section{Contents}

1. Introduction

2. Introduction of miRNAs

3. miRNAs in liver development and homeostasis

4. miRNAs and HCC development

5. miRNAs and clinical management of HCC

6. Conclusions and perspectives

\section{Introduction}

Hepatocellular carcinoma (HCC) is the sixth most common type of cancer and third-leading cause of cancer-related mortality worldwide (1). Despite the advances in the management of HCC over the last decade, persistent remissions are usually not achieved and the high invasiveness and metastatic

Correspondence to: Dr Hongchuan Jin, Department of Medical Oncology, Institute of Clinical Science, Sir Run Run Shaw Hospital, Medical School of Zhejiang University, 3 Qingchun East Road, Jianggan, Hangzhou, Zhejiang 310000, P.R. China

E-mail: zhedayue@163.com; jinhc@srrsh.com

Key words: microRNA, hepatocellular carcinoma, diagnosis, prognosis, therapy potential represent a major challenge in HCC treatment (2). Therefore, novel treatment options are required to improve the clinical outcome of HCC patients.

With the development of computational engines for microRNA (miRNA) target prediction, biochemical tools and techniques to modulate miRNA activity in vitro and in vivo, our knowledge of the miRNA field is rapidly expanding (3). miRNAs are a class of small non-coding RNAs that regulate a wide range of biological processes through altering the expression and translation of their target mRNA genes (4). Previous studies have demonstrated that miRNAs may be a potential target for cancer diagnosis and treatment. miRNAs, regulating $60 \%$ of human genes, are a powerful regulator of human physiological and pathological processes, including embryonic development, cell differentiation, tumorigenesis, cancer metastasis and tumor response to therapy (5-8). Thus, miRNAs may be used as diagnostic, prognostic and predictive biomarkers in cancer. Increasing evidence has demonstrated that abnormal expression of miRNAs in tumors results in the deregulation of the expression levels of oncogenes and tumor suppressors, which eventually promotes the proliferation of tumor cells (9-11). Therefore, miRNA-based anticancer therapies have emerged as an effective treatment option and may offer a curative potential in cancer therapy, either alone or in combination with other treatments (12). The aim of present study was to summarize the possible role of miRNA dysregulation in liver cancer and discuss the potential of miRNAs as diagnostic, prognostic and therapeutic biomarkers.

\section{Introduction of miRNAs}

The first small non-coding but functional RNAs to be identified over 20 years ago were lin-4 and let-7 $(13,14)$, which were first identified as regulators controlling developmental timing in the nematode Caenorhabditis elegans. Since then, extensive studies have been conducted to investigate the role of miRNAs in multiple biological processes, ranging from embryonic development to the pathogenesis of various diseases, including cancer (7,15-17).

The biogenesis of miRNAs involves multiple steps, including transcription, nuclear processing, export and cytoplasmic processing $(4,18)$. In the nucleus, miRNAs are transcribed as primary miRNA transcripts (pri-miRNAs) 
with 5 '-end caps and 3'-end poly-A tails, mainly by RNA polymerase II (19-21). Pri-miRNAs consist of $\geq 1$ hairpin structures, which finally become one or more functional miRNA(s) (22). The pri-miRNAs are located in intergenic and intragenic regions. The intergenic regions are processed by protein complexes, including nuclease, DiGeorge syndrome critical region gene 8 (DGCR8) and Drosha, while intragenic regions are processed by spliceosomes (23-25). Precursor miRNAs derived from the pri-miRNAs are exported from the nucleus to the cytoplasm by exportin-5 in a RanGTP-dependent manner (26), then further processed to the 22-nucleotide duplex by Dicer, a second RNase III endonuclease, and the double-stranded RNA-binding domain proteins TAR RNA-binding protein/protein activator of the interferon (IFN)-induced protein kinase, to form a duplex of mature miRNA. Constitutive disruption of either DGCR8 or Dicer, two key factors in the miRNA signaling pathway, results in a global loss of miRNAs (27). Ultimately, the miRNA duplex unwinds, and one of the strands associates with an argonaute protein within the RNA-induced silencing complex, where they direct gene expression by mRNA degradation or translational repression; the other miRNA strand is rapidly degraded (28).

\section{3. miRNAs in liver development and homeostasis}

As the largest gland in mammals, the liver serves as an endocrine and exocrine organ with numerous functions, including carbohydrate, lipid and amino acid metabolism, urea synthesis, detoxification of drugs and toxic endogenous compounds, bile production and plasma protein secretion (29). miRNAs play vital roles in several organ developmental and differentiation processes. Increasing evidence has demonstrated that miRNAs play an important role in regulating liver development and homeostasis (30). Hinton et al (27), Fu et al (31) and Kim et al (32) evaluated dynamic miRNA changes through analyzing definitive endoderm (DE) formation, murine and human embryonic stem cells (ESCs) and ESC-derived hepatocytes. The results of these previous studies indicated that different cell lines require definitive regulation by different miRNAs. For example, it is necessary that activin A-mediated $\mathrm{DE}$ formation is enhanced by the forced combined expression of RNAs, including miRNA (miR) 181, miR222, miR196a, miR196b, miR333-5p and let-7e. It was previously reported that a positive feedback loop between miR122 and hepatocyte nuclear factor 6 (HNF6) regulates proper hepatocyte-specific gene expression (33). During the process of liver differentiation and maturation, hepatoblasts exhibit morphological changes, such as epithelial-to-mesenchymal transition (EMT). Certain miRNAs are involved in the maintainance of the homeostasis of transition.

miR122, the most abundant miRNA in the liver, regulates the expression levels of 24 hepatocyte-specific genes, including HNF6, forkhead box protein A1 (FOXA1) and HNF4 $\alpha$. Furthermore, miR122 forms a positive feedback loop with FOXA1 and $\mathrm{HNF} 4 \alpha$ to regulate hepatocyte maturation (34). Several other miRNAs are involved in the regulation of liver development and differentiation, including miR148a (35) and miR33 (36).

As the central organ of metabolism in mammals, the liver synthesizes plasma proteins and bile acids, maintains the energy equilibrium and detoxifies metabolic wastes and xenobiotics.
The metabolism of glucose, the main energy source of the body, is primarily regulated by insulin and glucagon. The deletion of DICER1 in mouse liver led to severe hypoglycemia in the fasting state as a result of glycogen depletion (37). Several miRNAs are associated with glucose metabolism, including miR122, miR34a, miR103/107, let-7 and miR143 (38). It has also been reported that miR 122 and $\mathrm{miR} 27 \mathrm{~b}$ are associated with lipid metabolism, miR122, miR485-3p and let-7 are involved in iron metabolism, while miR132/142-3p/21, miR142-3p/21 and $\mathrm{miR} 130 \mathrm{~b} / 185 / 34 \mathrm{a}$ are involved in the metabolism of drugs and xenobiotic substances (39). In conclusion, miRNAs play pivotal roles in regulating multiple aspects of liver physiology.

\section{4. miRNAs and HCC development}

As the miRNAs are vital regulators of liver function, their dysregulation is associated with liver dysfunction. HCC is the main type of liver cancer and the third most common cause of cancer-related mortality worldwide. miRNAs are often deregulated in HCC, and certain specific miRNAs are associated with the clinicopathological characteristics of HCC. It was recently demonstrated that miRNAs play critical roles in HCC progression and directly contribute to tumor cell proliferation, avoidance of apoptotic cell death and metastasis by targeting a large number of specific mRNAs. miRNAs may undergo aberrant regulation during carcinogenesis and act as oncogenes or tumor suppressor genes (30,40-43).

Chronic hepatitis caused by hepatotropic viruses, namely hepatitis $\mathrm{B}$ virus (HBV) and hepatitis $\mathrm{C}$ virus (HCV), are a major risk factor for HCC (44) and may affect the course of liver tumor development (45). Numerous genetic and epigenetic alterations are involved in hepatocellular carcinogenesis. Park et al (46) demonstrated that the inflammatory responses induced by obesity or administration of diethylnitrosamine contribute to HCC development in mice.

It was previously indicated that transient inhibition of HNF4 $\alpha$, which is essential for liver development and hepatocyte function, initiates hepatocellular transformation through an miRNA-inflammatory feedback loop circuit consisting of miR124, interleukin 6 receptor (IL6R), signal transducer and activator of transcription 3 (STAT3), miR24 and miR629 (47). In this feedback loop circuit, miR24 and miR629 inhibit HNF4 $\alpha$ expression, directly resulting in hepatocellular transformation. STAT3 is a direct regulator of miR24 and miR629 expression, the increase of which exerts vital effects on HCC initiation. As a direct downstream effector of HNF4 $\alpha$ activity, miR124 targets IL6R and consequently modulates the IL6R/STAT3 pathway during hepatocellular transformation. The activation of this circuit suppresses HNF4 $\alpha$ expression to sustain oncogenesis. Administration of miR124, a modulator of inflammatory signaling, induces tumor-specific apoptosis, thus suppressing hepatocellular carcinogenesis. Accordingly, manipulation of this miRNA feedback inflammatory loop may be of clinical value in the treatment of liver cancer. In order to elucidate the mechanisms underlying the effect of miRNAs on HCC development, some of the associated miRNAs are summarized below.

miRNAs and hepatic cancer stem cells (CSCs). Mounting evidence in cancer biology indicates that a small population of cells in tumor tissues, referred to as CSCs, have the ability to 
maintain tumorigenesis (44). CSCs in the liver sustain tumor formation and development and endow tumor cells with stem cell properties $(49,50)$.

As a result of the high renewal capacity, currently available chemotherapeutic and radiotherapeutic regimens fail to eliminate the bulk of cancer cells $(51,52)$. Several signaling pathways, including MET, MYC, transforming growth factor- $\beta$, Hedgehog, p53, WNT/ $\beta$-catenin and epidermal growth factor, have been demonstrated in hepatocarcinogenesis, a number of which may overlap with other pathways associated with hepatic progenitor cells (53). According to Oishi and Wang (54), hepatic progenitor cells are considered to be the origin of a proportion of HCCs, whereas miR181 may be involved in HCC progression by targeting HCC CSCs. Ji et al (55) demonstrated that conserved miR181 family members were highly expressed in embryonic livers and isolated hepatic stem cells using a global microarray-based miRNA profiling approach, followed by validation with reverse transcription quantitative polymerase chain reaction (RT-qPCR).

Furthermore, deletion of miR181 resulted in a reduction in the number of $\mathrm{HCC}$ cells and tumor-initiating ability; however, exogenous miR181 expression in HCC cells restored their growth. miR181 has been found to directly target hepatic transcriptional regulators of differentiation and is an inhibitor of WNT/ $\beta$-catenin signaling. It may be concluded that miR181 is involved in the regulation of human liver CSCs (55). Therefore, miRNAs are vital regulators of the maintainance of stemness characteristics of hepatic CSCs through modulation of tumor-suppressive and oncogenic signaling pathways associated with tumorigenesis and tumor development.

miRNAs and cell cycle regulation. As defects in cell cycle control are among the hallmarks of HCC, multiple tumor activators and suppressors involved in cell cycle regulation are often aberrantly targeted by deregulated miRNAs in HCC. For example, regulated miRNAs may target essential cell cycle regulators, including cell cycle inhibitors of the cyclin-dependent kinase (CDK) interacting protein/kinase inhibitory protein family, cyclin-CDK complexes, the phosphoinositide 3-kinase/Akt/mammalian target of rapamycin signaling cascade, and other cell growth regulatory genes (43). The direct targets of miR26a involved in the cell cycle are cyclins D2 and E2, from a family of proteins that control cell cycle progression by activating CDK cyclins, which exhibit reduced expression in HCC (56). The expression of miR26a induces HCC cell cycle arrest through direct targeting of these two cyclins.

miR122 suppresses HCC cell growth by directly targeting cyclin G1 expression (57). miR122 shortens the G2-M phase, leading to a reduction in the invasive ability of HCC-derived cells through modulating cyclin G1, p53 protein stability and transcriptional activity (58). In addition, miR124, which is silenced through $\mathrm{CpG}$ methylation in HCC, targets CDK6 to induce cell cycle arrest at the G1-S checkpoint (59).

miRNAs and apoptosis. The ability to escape apoptosis enables tumor cells to survive in the tumor environment, even after invading distal tissue. Cytochrome $c$, a potent catalyst of apoptosis, is released from mitochondria when proapoptotic signals emerge. An increasing number of studies have demonstrated that miRNAs play an important role in regulating the B-cell lymphoma-2 (Bcl-2) family of proteins, which are associated with mitochondrial apoptosis signaling. The Bcl-2 protein family includes Bcl-2-interacting mediator of cell death (Bim), Bcl-2-modifying factor (Bmf), Bcl-2, Bcl-2-like protein 2 $(\mathrm{Bcl}-\mathrm{W}), \mathrm{Bcl}-\mathrm{extra}$ large $(\mathrm{Bcl}-\mathrm{XL})$ and myeloid leukemia cell differentiation protein (Mcl-1). Shimizu et al (60) demonstrated that the let-7 family of miRNAs enhanced sorafenib-induced apoptosis by repressing Bcl-XL expression in HCC. miR29 may promote apoptosis by targeting Mcl-1 and Bcl-2 in the mitochondrial pathway (61). Therefore, upregulated let-7 and miR29 expression may improve the sensitivity of HCC cells to certain apoptotic signals, thus exerting antitumor effects. Bcl-2, Bcl-W, Bcl-XL and Mcl-1 exert antiapoptotic effects; however, Bim and Bmf exert a proapoptotic effect. miR221 and miR25 exert their antiapoptotic effect through targeting and inhibiting Bmf and Bim, respectively $(62,63)$. Other apoptosis-related genes are also targeted by miRNAs. Yang et al (64) reported that miR602 repressed HCC cell apoptosis by inhibiting Ras association domain family 1 , isoform A. In addition to cell cycle regulation, miR 221 and miR222 render tumor cells more resistant to tumor necrosis factor-related apoptosis-inducing ligand-induced apoptosis through inhibiting the expression of phosphatase and tensin homolog (PTEN) and metalloproteinase inhibitor 3 (65).

miRNAs and cancer metastasis. The aberrant expression of miRNAs has been found to be closely associated with HCC cell metastasis (66). Among these miRNAs, the reduced expression of miR122 in HCC may suppress the hepatic phenotype and enhance the metastatic properties of HCC (67). miR34a downregulates c-Met in HCC, resulting in the reduction of cell migration and invasion (68). By contrast, miR21 promotes cell growth, invasion and metastasis by inhibiting PTEN gene activity in HCC (69). miR224 was found to be highly expressed during extensive metastasis of HCC (70). Li et al (71) confirmed that miR224 promotes the expression of the tumor invasion-associated proteins phosphorylated-p21-activated kinase 4 and matrix metalloproteinase- 9 by directly targeting homeobox D10. A series of miRNAs, including 3 upregulated miRNAs (miR10a, miR100 and miR122) and 2 downregulated miRNAs (miR145 and miR198), were found to be expressed in HCV-HCC tissues, but not in normal liver parenchyma (72). In addition, decreased levels of miR126 have been specifically observed in the HCC subgroups associated with alcohol consumption (73).

Other miRNAs are also involved in the regulation of HCC invasion and metastasis, including miR17-5p (74), miR30d (75) and miR151 (76). In conclusion, miRNAs may be considered as a neoteric modulator of tumor cell migration and invasion in HCC, and provide a novel approach to the treatment of HCC. More miRNAs involved in HCC development are listed in Table I.

\section{5. miRNAs and clinical management of HCC}

miRNAs for HCC diagnosis. Due to the lack of reliable markers for early diagnosis, the overall 5-year survival rate of HCC remains extremely low (77). Liver damage induced by multiple agents, ranging from chemicals to viruses, is clinically 
evaluated by measurement of serum aminotransferase levels (alanine and aspartate aminotransferase). However, these markers are associated with several limitations, including the requirement of fresh blood samples, lack of tissue specificity, and the inability to distinguish between hepatocyte damage and inflammation. Similarly, the marker $\alpha$-fetoprotein, traditionally used to monitor patients at high risk of HCC, may only be detected in a proportion of HCC patients, with an associated risk of false-negative and -positive results (78). Therefore, there is an urgent need for novel molecular biomarkers to assist in the early diagnosis and prognosis of HCC. Increasing evidence suggests that unique miRNA signatures may serve as valuable diagnostic and prognostic biomarkers in HCC (79).

miRNAs are present in various body fluids, including serum and plasma $(80,81)$. Furthermore, miRNAs exhibit significant stability under extreme conditions, such as low $\mathrm{pH}$ (acidic environment) and resistance to RNAase, and are considered as alternative non-invasive biomarkers $(80,82)$. Several studies have demonstrated that specific circulating miRNAs are present in various diseases $(81,82)$. The abovementioned traits of miRNAs render them optimal biomarkers for liver diseases.

Since miRNAs have the advantages of being released from cancer cells into body fluids, accessible non-invasiveness and stability, a number of unique circulating miRNAs have the potential to serve as diagnostic markers for HCC. In 2010, Li et al (83) employed a 'proof-of-principle' approach, which included Solexa sequencing of pooled serum samples, followed by multiple RT-qPCR validation sets at an individual level, and identified unique expression profiles for $\mathrm{HBV}$ - and $\mathrm{HCC}$-related serum miRNAs. Ultimately, the results suggested that let-7f, miR25 and miR375 may distinguish HCC patients from healthy subjects [area under the curve $(\mathrm{AUC})=99.67 \pm 0.15 \%$; sensitivity, 97.9\%; and specificity, 99.1\%] (83). Additionally, miR23a, miR23b, miR342-3p, miR375 and miR423 may differentiate between $\mathrm{HBV}$-positive $\mathrm{HCC}$ patients and control subjects (AUC $=99.9 \pm 0.1 \%$; sensitivity, 96.9\%; and specificity, 99.4\%) (83). Zhou et al (84) made these findings more comprehensive in another study; their results suggested that a 7-miRNA signature, including 3 upregulated miRNAs (miR21, miR192 and miR801) and 4 downregulated miRNAs (miR26a, miR27a, miR122 and miR223), may be used to distinguish HCC patients from healthy subjects, chronic hepatitis B and cirrhosis patients. Together with other biochemical tests, quantitative analysis of circulating miRNA may significantly improve the early detection rate and screening of potential HCC patients.

miRNAs for prediction of prognosis in HCC. In recent years, an increasing number of studies have indicated that miRNAs may be applied not only as diagnostic biomarkers, but also as prognostic factors for cancer. Identifying relevant biomarkers may help classify patients at a higher risk for tumor recurrence following radical resection for HCC. Furthermore, relevant biomarkers play a pivotal role in improving the therapeutic strategies for patients with early-stage disease, without evident vascular invasion, regional lymph node or distant metastasis (85). In order to simplify the evaluation of prognostic miRNA signatures in cancer, Aguirre-Gamboa et al (86) developed SurvMicro, a freely accessible and easy to use web tool that assesses miRNA signatures from publicly available miRNA profiles using multivariate survival analysis. SurvMicro consists of a wide and updated database of $>40$ cohorts in different tissues, and is a bioinformatics tool that aids the evaluation of multivariate prognostic miRNA signatures in several types of cancer, including HCC. This bioinformatics tool provides strong evidence regarding the potential of miRNAs as biomarkers for the prognosis of HCC.

Of note, Zhu et al (87) reported that the expression of miR29a-5p in formalin-fixed paraffin-embedded HCC tissues may provide useful information for predicting early recurrence following HCC resection through studying two independent large cohorts of patients with long-term follow-up; they found that the sensitivity and specificity of miR29a-5p as a predictor of early recurrence of Barcelona Clinic Liver Cancer stage 0/A HCC were 74.2 and $68.2 \%$, respectively, by multivariate analysis. However, the mechanism underlying the involvement of miR29a-5p in early recurrence of HCC has not yet been elucidated, although it may include HCC invasion and metastasis, which are the main causes of early recurrence following HCC resection $(88,89)$. In addition, other miRNAs are considered as potential biomarkers for the prognosis of HCC. For example, downregulation of the expression of miR26 indicates that HCC patients are sensitive to IFN- $\alpha$ therapy (90). A characteristic feature of tumors with low miR26 expression is unique activation of IFN- $\alpha$ signaling via the nuclear factor- $\kappa$ B-IL-6 signaling pathway. As a consequence, $\mathrm{HCC}$ cells exhibiting low expression of miR26 become more sensitive to growth repression by IFN- $\alpha$ through IL-6-STAT3 signaling. In conclusion, miRNA profiling may be able to predict clinical response to therapy for HCC and provide novel prognostic tools, paving the way for the personalized therapy of HCC patients.

miRNAs in HCC treatment. The mechanisms underlying miRNAs acting as regulators of multiple aspects of liver development is an appealing research focus in HCC treatment. Preclinical models constructed to elucidate the biological role of any specific miRNA lay the foundation for the emergence of the first indications of the feasibility and efficacy of miRNA-based therapy in cancer. The strategies targeting miRNA expression in HCC mainly encompass direct and indirect methods of preventing the expression of an oncogenic miRNAs or reintroducing a tumor suppressor miRNA that is lost in cancer, and using drugs to modulate miRNA expression by separately targeting their transcription and processing. For example, silencing oncogenic miR221 generates a proapoptotic and antiproliferative response in vitro in different cellular models of HCC (91), while reinduction of miR26a suppresses cancer cell proliferation and activates tumor-specific apoptosis in vivo, resulting in significant suppression of tumor progression without toxicity (57). By contrast, miRNAs may be used as adjuvant tools, largely due to their involvement in specific networks, including apoptosis, proliferation, or receptor-driven pathways. Therefore, miRNAs may affect the response of HCC to targeted therapy or chemotherapy. Xu et al (92) demonstrated that miR122 renders HCC cells sensitive to Adriamycin ${ }^{\circledR}$ and vincristine by reducing the expression of multidrug resistance-related genes, including the antiapoptotic genes Bcl-W and cyclin B1. DNA methylation of miR193a-3p enhances the resistance of HCC cells to 5-fluorouracil through 
Table I. Dysregulated microRNAs in hepatocellular carcinoma.

\begin{tabular}{|c|c|c|c|c|}
\hline \multirow[b]{2}{*}{ Function } & \multicolumn{2}{|l|}{ Upregulated } & \multicolumn{2}{|c|}{ Downregulated } \\
\hline & $\operatorname{miRs}$ & References & miRs & References \\
\hline Proliferation & $\begin{array}{l}\operatorname{miR} 155, \operatorname{miR} 18 a, \operatorname{miR} 210, \\
\operatorname{miR} 221, \operatorname{miR} 224, \operatorname{miR} 519 d \\
\operatorname{miR} 590-5 p\end{array}$ & $(101-108)$ & $\begin{array}{l}\text { let-7a, let-7b, let-7c, } \\
\text { let-7d, let-7f-1, miR1, } \\
\text { miR124, miR200a,miR203, } \\
\text { miR219-5p, miR223, miR376a, } \\
\text { miR449, miR450a, miR520b }\end{array}$ & $(109-122)$ \\
\hline Apoptosis & $\begin{array}{l}\operatorname{miR} 210, \operatorname{miR} 221, \operatorname{miR} 224, \\
\text { miR519d }\end{array}$ & $\begin{array}{l}(58,62,91, \\
105-107 \\
123,124)\end{array}$ & $\begin{array}{l}\text { let-7a, let-7b, let-7c, let-7d, } \\
\text { let-7f-1, miR101, miR122, } \\
\text { miR125b, miR195, miR376a, } \\
\text { miR449 }\end{array}$ & $\begin{array}{l}(60,109,111 \\
115-117,122 \\
125-137)\end{array}$ \\
\hline Cell cycle & $\operatorname{miR} 373$ & $(140)$ & $\mathrm{miR} 138, \mathrm{miR} 195, \mathrm{miR} 26 \mathrm{a} / \mathrm{b}$ & $(134,138,139)$ \\
\hline Metastasis & $\begin{array}{l}\operatorname{miR} 10 a, \operatorname{miR} 135 a, \operatorname{miR} 143, \\
\text { miR181b, miR182, miR21, } \\
\text { miR200a, miR210, miR224, } \\
\text { miR301a, miR550a, } \\
\text { miR590-5p }\end{array}$ & $\begin{array}{l}(68,69,105 \\
107,120 \\
144-157)\end{array}$ & $\begin{array}{l}\text { let-7g, miR } 122, \text { miR125a, } \\
\text { miR125b, miR139, miR3a, } \\
\text { miR7 }\end{array}$ & $\begin{array}{l}(109,114,126, \\
133,141-143)\end{array}$ \\
\hline
\end{tabular}

miR, microRNA.

downregulation of the serine/arginine-rich splicing factor 2, resulting in upregulation of the proapoptotic splicing form of caspase 2 (93). IFN is widely employed in the treatment of HCC. However, miR146a induces resistance of HCC cells to IFN- $\alpha$ by downregulating mothers against decapentaplegic homolog 4 (94).

miRNAs may alter the sensitivity of tumor cells to chemotherapy and/or radiotherapy. Weidhaas et al (95) reported that specific inhibition of miR210 may increase the sensitivity of HCC cells to radiotherapy. A direct target of miR210 in human HCC cells is apoptosis-inducing factor M3 (AIFM3), also referred to as AIF-like, as it is a gene homolog of AIF. AIFM3 is mainly present in mitochondria, resulting in cytochrome $c$ release and apoptosis in a caspase-dependent manner $(96,97)$. AIFM3 downregulation by small interfering RNA-impaired radiation-induced apoptosis in human HCC cells was associated with reduced miR 210 expression. miR210 downregulation enhances radiation-induced apoptosis in human HCC cells by targeting the AIFM3 gene (95). Therefore, specific regulation of miRNAs in combination with radiotherapy may be expected to exert strong antitumor effects on HCC cells.

Therapies based on directly targeting miRNAs are faced with several challenges. First, steadily and effectively delivering a therapeutic RNA to target tissues remains a major obstacle. A direct method is difficult, since it would involve exiting the circulatory system, transiting the cell membrane, escaping from endosomal vesicles into the cytoplasm and avoiding being filtered and excreted by the kidney. In addition, escaping removal by phagocytic immune cells in the bloodstream, such as macrophages and monocytes, is another challenge.

A number of studies have investigated methods to overcome these difficulties. Among the established approaches to in vivo delivery of miRNAs, adeno-associated viral vectors have been considered to be a promising therapeutic strategy for cancer, due to the lower risk of vector-related toxicities and the higher gene transfer efficacy (57,98). In 2009, Kota et al (56) utilized an adeno-associated virus carrying the miR26a gene to infect a mouse model of HCC, resulting in the inhibition of cancer cell proliferation and induction of tumor-specific apoptosis. However, the utilization of a viral system to reintroduce an miRNA is inevitably associated with certain shortcomings. The delivered material may be integrated into the host DNA or remain episomal, depending upon the nature of the system. For example, retroviral and lentiviral vectors integrate their DNA into the host genome, resulting in the risk of insertional mutagenesis and activation of protooncogenes due to the unpredictable site of integration. In addition to miRNA delivery using viral vectors, artificially synthesized miRNA or anti-miRNA oligonucleotides (AMOs) are other noteworthy therapeutic approaches (99). Since synthesized miRNA or AMOs consist of single-stranded 2'- $O$-methyl-modified antisense oligonucleotides fully complementary to the predicted miRNA binding sites in the 3'-untranslated region of a specific target mRNA, this strategy may markedly reduce unwanted or off-target effects. Hatakeyama et al (100) encapsulated AMOs including 2-O-methyl and phosphorothioate modifications against miR122 (AMO122) into the YSK05-MEND, which is a pH-sensitive multifunctional envelope-type nanodevice (MEND) containing a pH-sensitive lipid YSK05. YSK05-MEND was then utilized to regulate liver-specific miR122. Compared with Lipofectamine ${ }^{\circledR} 2000$ (LFN2k), YSK05-MEND displayed a higher activity in liver cancer cells due to efficient endosomal escape, despite the lower uptake. Furthermore, YSK05-MEND exhibited minimal cytotoxicity at $100 \mathrm{nM}$ of AMO122 in treated cells, whereas LFN2k exhibited cytotoxicity at $50 \mathrm{nM}$. Compared with free AMO122, the YSK05-MEND delivered higher amounts of AMO122 to the liver. In addition, free AMO122 is more 
easily eliminated via the kidney due to its molecular weight. The dose at which systemic administration of YSK05-MEND results in the knockdown of miR122 and an increase in target gene expression in the liver, with a subsequent reduction of plasma cholesterol, is significantly lower compared with that of free AMO122. The duration of the effect of AMO122 delivered by YSK05-MEND is also longer compared with that of free AMO122. In conclusion, these results suggest that YSK05-MEND is a promising system for in vivo delivery of AMOs to the liver (100).

\section{Conclusions and perspectives}

Small non-coding RNAs as regulators of gene expression have been demonstrated to be involved in all biological systems. Several miRNAs are deregulated to promote hepatocellular carcinogenesis through inducing translational inhibition and degradation of target mRNAs critical for HCC development. miRNAs may be used as biomarkers for diagnosis and prognosis and may be a potential therapeutic tool for HCC. Although significant progress has been achieved in the miRNA field, a number of questions remain to be further elucidated. Undoubtedly, the identification of novel miRNAs and novel miRNA functions in liver development and abnormity pave the way to designing effective and safe strategies for the diagnosis and treatment of this life-threatening disease. With the identification of HCC-associated miRNA signatures and the overcoming of certain obstacles, including unwanted off-target effects and inefficient miRNA delivery, the use of miRNAs as a diagnostic and therapeutic tool in HCC appears to be a promising research focus in the immediate future.

\section{Acknowledgements}

This study was supported by grants from the Department of Health of Zhejiang Province (nos. WKJ2012-2-013 and 2013RCA029) and the 973 Program of the Ministry of Science and Technology of P.R. China (no. 2012CB526600).

\section{References}

1. Forner A, Llovet JM and Bruix J: Hepatocellular carcinoma. Lancet 379: 1245-1255, 2012.

2. Lai EC and Lau WY: The continuing challenge of hepatic cancer in Asia. Surgeon 3: 210-215, 2005.

3. Sotillo E and Thomas-Tikhonenko A: Shielding the messenger (RNA): microRNA-based anticancer therapies. Pharmacol Ther 131: 18-32, 2011.

4. Bartel DP: MicroRNAs: genomics, biogenesis, mechanism, and function. Cell 116: 281-297, 2004.

5. Friedman RC, Farh KK, Burge CB and Bartel DP: Most mammalian mRNAs are conserved targets of microRNAs. Genome Res 19: 92-105, 2009.

6. Li Y and Kowdley KV: Cellular microRNA and the tumorigenesis of hepatocellular carcinoma. Ann Hepatol 11: 272-274, 2012.

7. Pauli A, Rinn JL and Schier AF: Non-coding RNAs as regulators of embryogenesis. Nat Rev Genet 12: 136-149, 2011.

8. Poy MN, Eliasson L, Krutzfeldt J, et al: A pancreatic islet-specific microRNA regulates insulin secretion. Nature 432 226-230, 2004

9. Chen CZ: MicroRNAs as oncogenes and tumor suppressors. N Engl J Med 353: 1768-1771, 2005.

10. Esquela-Kerscher A and Slack FJ: Oncomirs - microRNAs with a role in cancer. Nat Rev Cancer 6: 259-269, 2006.

11. Hammond SM: MicroRNAs as tumor suppressors. Nat Genet 39: 582-583, 2007.
12. Iorio MV and Croce CM: MicroRNA dysregulation in cancer: diagnostics, monitoring and therapeutics. A comprehensive review. EMBO Mol Med 4: 143-159, 2012.

13. Lee RC, Feinbaum RL and Ambros V: The C. elegans heterochronic gene lin-4 encodes small RNAs with antisense complementarity to lin-14. Cell 75: 843-854, 1993.

14. Reinhart BJ, Slack FJ, Basson M, et al: The 21-nucleotide let-7 RNA regulates developmental timing in Caenorhabditis elegans. Nature 403: 901-906, 2000.

15. Fabian MR and Sonenberg N: The mechanics of miRNA-mediated gene silencing: a look under the hood of miRISC. Nat Struct Mol Biol 19: 586-593, 2012.

16. Filipowicz W, Bhattacharyya SN and Sonenberg N: Mechanisms of post-transcriptional regulation by microRNAs: are the answers in sight? Nat Rev Genet 9: 102-114, 2008.

17. Rinn JL and Chang HY: Genome regulation by long noncoding RNAs. Annu Rev Biochem 81: 145-166, 2012.

18. Garzon R, Calin GA and Croce CM: MicroRNAs in cancer. Annu Rev Med 60: 167-179, 2009.

19. Borchert GM, Lanier W and Davidson BL: RNA polymerase III transcribes human microRNAs. Nat Struct Mol Biol 13: 1097-1101, 2006.

20. Cai X, Hagedorn $\mathrm{CH}$ and Cullen BR: Human microRNAs are processed from capped, polyadenylated transcripts that can also function as mRNAs. RNA 10: 1957-1966, 2004.

21. Lee Y, Kim M, Han J, et al: MicroRNA genes are transcribed by RNA polymerase II. EMBO J 23: 4051-4060, 2004.

22. Kim VN, Han J and Siomi MC: Biogenesis of small RNAs in animals. Nat Rev Mol Cell Biol 10: 126-139, 2009.

23. Berezikov E, Chung WJ, Willis J, Cuppen E and Lai EC: Mammalian mirtron genes. Mol Cell 28: 328-336, 2007.

24. Lee Y, Ahn C, Han J, et al: The nuclear RNase III Drosha initiates microRNA processing. Nature 425: 415-419, 2003.

25. Ruby JG, Jan CH and Bartel DP: Intronic microRNA precursors that bypass Drosha processing. Nature 448: 83-86, 2007.

26. Berezikov E, Guryev V and Cuppen E: Exploring conservation of transcription factor binding sites with CONREAL. Methods Mol Biol 395: 437-448, 2007.

27. Hinton A, Afrikanova I, Wilson M, et al: A distinct microRNA signature for definitive endoderm derived from human embryonic stem cells. Stem Cells Dev 19: 797-807, 2010.

28. Kim Y and Kim VN: MicroRNA factory: RISC assembly from precursor microRNAs. Mol Cell 46: 384-386, 2012.

29. Si-Tayeb K, Lemaigre FP and Duncan SA: Organogenesis and development of the liver. Dev Cell 18: 175-189, 2010.

30. Chen Y and Verfaillie CM: MicroRNAs: the fine modulators of liver development and function. Liver Int 34: 976-990, 2014.

31. Fu S, Fei Q, Jiang H, et al: Involvement of histone acetylation of Sox 17 and Foxa 2 promoters during mouse definitive endoderm differentiation revealed by microRNA profiling. PLoS One 6: e27965, 2011.

32. Kim N, Kim H, Jung I, Kim Y, Kim D and Han YM: Expression profiles of miRNAs in human embryonic stem cells during hepatocyte differentiation. Hepatol Res 41: 170-183, 2011.

33. LaudadioI, Manfroid I, Achouri Y, et al: A feedback loop between the liver-enriched transcription factor network and miR-122 controls hepatocyte differentiation. Gastroenterology 142: 119-129, 2012.

34. $\mathrm{Xu} \mathrm{H}, \mathrm{He} \mathrm{JH}, \mathrm{Xiao} \mathrm{ZD}$, et al: Liver-enriched transcription factors regulate microRNA-122 that targets CUTL1 during liver development. Hepatology 52: 1431-1442, 2010.

35. Gailhouste L, Gomez-Santos L, Hagiwara K, et al: miR-148a plays a pivotal role in the liver by promoting the hepatospecific phenotype and suppressing the invasiveness of transformed cells. Hepatology 58: 1153-1165, 2013.

36. Allen RM, Marquart TJ, Albert CJ, et al: miR-33 controls the expression of biliary transporters, and mediates statin- and diet-induced hepatotoxicity. EMBO Mol Med 4: 882-895, 2012.

37. Hand NJ, Master ZR, Le Lay J and Friedman JR: Hepatic function is preserved in the absence of mature microRNAs. Hepatology 49: 618-626, 2009.

38. Yang YM, Seo SY, Kim TH and Kim SG: Decrease of microRNA-122 causes hepatic insulin resistance by inducing protein tyrosine phosphatase $1 \mathrm{~B}$, which is reversed by licorice flavonoid. Hepatology 56: 2209-2220, 2012.

39. Rieger JK, Klein K, Winter S and Zanger UM: Expression variability of absorption, distribution, metabolism, excretion-related microRNAs in human liver: influence of nongenetic factors and association with gene expression. Drug Metab Dispos 41: 1752-1762, 2013. 
40. Chai ZT, Kong J, Zhu XD, Zhang YY, Lu L, Zhou JM, Wang LR, Zhang KZ, Zhang QB, Ao JY, et al: MicroRNA-26a inhibits angiogenesis by down-regulating VEGFA through the PIK3C2 $\alpha /$ Akt/HIF-1 $\alpha$ pathway in hepatocellular carcinoma. PLoS One 8: e77957, 2013.

41. Yang H, Cho ME, Li TW, Peng H, Ko KS, Mato JM and Lu SC: MicroRNAs regulate methionine adenosyltransferase $1 \mathrm{~A}$ expression in hepatocellular carcinoma. J Clin Invest 123 285-98, 2013

42. Zhang Y, Yang P and Wang XF: Microenvironmental regulation of cancer metastasis by miRNAs. Trends Cell Biol 24 153-60, 2014

43. Huang $\mathrm{S}$ and $\mathrm{He} \mathrm{X}$ : The role of microRNAs in liver cancer progression. Br J Cancer 104: 235-240, 2011.

44. El-Serag HB and Rudolph KL: Hepatocellular carcinoma: epidemiology and molecular carcinogenesis. Gastroenterology 132 2557-2576, 2007.

45. Coussens LM and Werb Z: Inflammation and cancer. Nature 420: 860-867, 2002.

46. Park EJ, Lee JH, Yu GY, et al: Dietary and genetic obesity promote liver inflammation and tumorigenesis by enhancing IL-6 and TNF expression. Cell 140: 197-208, 2010.

47. Hatziapostolou M, Polytarchou C, Aggelidou E, et al: An HNF4 $\alpha$-miRNA inflammatory feedback circuit regulates hepatocellular oncogenesis. Cell 147: 1233-1247, 2011.

48. Ma S, Chan KW, Hu L, et al: Identification and characterization of tumorigenic liver cancer stem/progenitor cells Gastroenterology 132: 2542-2556, 2007.

49. Ma S, Lee TK, Zheng BJ, Chan KW and Guan XY: CD133 HCC cancer stem cells confer chemoresistance by preferential expression of the Akt/PKB survival pathway. Oncogene 27: 1749-1758, 2008.

50. Wang Y, Yu Y, Tsuyada A, et al: Transforming growth factor- $\beta$ regulates the sphere-initiating stem cell-like feature in breast cancer through miRNA-181 and ATM. Oncogene 30: 1470-1480, 2011.

51. Gupta PB, Onder TT, Jiang G, et al: Identification of selective inhibitors of cancer stem cells by high-throughput screening. Cell 138: 645-659, 2009

52. Morrison R, Schleicher SM, Sun Y, et al: Targeting the mechanisms of resistance to chemotherapy and radiotherapy with the cancer stem cell hypothesis. J Oncol 2011: 941876, 2011.

53. Pardal R, Clarke MF and Morrison SJ: Applying the principles of stem-cell biology to cancer. Nat Rev Cancer 3: 895-902, 2003.

54. Oishi $\mathrm{N}$ and Wang XW: Novel therapeutic strategies for targeting liver cancer stem cells. Int J Biol Sci 7: 517-535, 2011.

55. Ji J, Yamashita T, Budhu A, et al: Identification of microRNA-181 by genome-wide screening as a critical player in EpCAM-positive hepatic cancer stem cells. Hepatology 50: 472-480, 2009.

56. Kota J, Chivukula RR, O'Donnell KA, et al: Therapeutic microRNA delivery suppresses tumorigenesis in a murine liver cancer model. Cell 137: 1005-1017, 2009.

57. Gramantieri L, Ferracin M,Fornari F, et al: Cyclin G1 is a target of miR-122a, a microRNA frequently down-regulated in human hepatocellular carcinoma. Cancer Res 67: 6092-6099, 2007

58. Fornari F, Gramantieri L, Giovannini C, et al: MiR-122/cyclin G1 interaction modulates p53 activity and affects doxorubicin sensitivity of human hepatocarcinoma cells. Cancer Res 69 $5761-5767,2009$

59. Furuta M, Kozaki KI, Tanaka S, Arii S, Imoto I and Inazawa J: miR-124 and miR-203 are epigenetically silenced tumor-suppressive microRNAs in hepatocellular carcinoma Carcinogenesis 31: 766-776, 2010.

60. Shimizu S, Takehara T, Hikita $\mathrm{H}$, et al: The let-7 family of microRNAs inhibits Bcl-xL expression and potentiates sorafenib-induced apoptosis in human hepatocellular carcinoma. J Hepatol 52: 698-704, 2010.

61. Xiong Y, Fang JH, Yun JP, et al: Effects of microRNA-29 on apoptosis, tumorigenicity, and prognosis of hepatocellular carcinoma. Hepatology 51: 836-845, 2010.

62. Gramantieri L, Fornari F, Ferracin M, et al: MicroRNA-221 targets Bmf in hepatocellular carcinoma and correlates with tumor multifocality. Clin Cancer Res 15: 5073-5081, 2009.

63. Li Y, Tan W, Neo TW, et al: Role of the miR-106b-25 microRNA cluster in hepatocellular carcinoma. Cancer Sci 100: 1234-1242, 2009

64. Yang L, Ma Z, Wang D, Zhao W, Chen L and Wang G: MicroRNA-602 regulating tumor suppressive gene RASSF1A is overexpressed in hepatitis B virus-infected liver and hepatocellular carcinoma. Cancer Biol Ther 9: 803-808, 2010.
65. Garofalo M,Di Leva G, Romano G, et al: miR-221\&222 regulate TRAIL resistance and enhance tumorigenicity through PTEN and TIMP3 downregulation. Cancer Cell 16: 498-509, 2009.

66. Gramantieri L, Fornari F, Callegari E, et al: MicroRNA involvement in hepatocellular carcinoma. J Cell Mol Med 12: 2189-2204, 2008

67. Coulouarn C, Factor VM, Andersen JB, Durkin ME and Thorgeirsson SS: Loss of miR-122 expression in liver cancer correlates with suppression of the hepatic phenotype and gain of metastatic properties. Oncogene 28: 3526-3536, 2009.

68. Li N, Fu H, Tie Y, et al: miR-34a inhibits migration and invasion by down-regulation of c-Met expression in human hepatocellular carcinoma cells. Cancer Lett 275: 44-53, 2009.

69. Meng F, Henson R, Wehbe-Janek H, Ghoshal K, Jacob ST and Patel T: MicroRNA-21 regulates expression of the PTEN tumor suppressor gene in human hepatocellular cancer. Gastroenterology 133: 647-658, 2007.

70. Lin SL, Miller JD and Ying SY: Intronic microRNA (miRNA). J Biomed Biotechnol 2006: 26818, 2006.

71. Li Q, Ding C, Chen C, et al: miR-224 promotes cell migration and invasion by targeting Homeobox D 10 gene in human hepatocellular carcinoma. J Gastroenterol Hepatol 29: 835-842, 2014.

72. Varnholt H, Drebber U, Schulze F, et al: MicroRNA gene expression profile of hepatitis $C$ virus-associated hepatocellular carcinoma. Hepatology 47: 1223-1232, 2008.

73. Ladeiro Y, Couchy G, Balabaud C, et al: MicroRNA profiling in hepatocellular tumors is associated with clinical features and oncogene/tumor suppressor gene mutations. Hepatology 47: 1955-1963, 2008

74. Yang F, Yin Y, Wang F, et al: miR-17-5p Promotes migration of human hepatocellular carcinoma cells through the p38 mitogen-activated protein kinase-heat shock protein 27 pathway. Hepatology 51: 1614-1623, 2010.

75. Ding J, Huang S, Wu S, et al: Gain of miR-151 on chromosome 8q24.3 facilitates tumour cell migration and spreading through downregulating RhoGDIA. Nat Cell Biol 12: 390-399, 2010.

76. Yao J, Liang L, Huang S, et al: MicroRNA-30d promotes tumor invasion and metastasis by targeting Galphai2 in hepatocellular carcinoma. Hepatology 51: 846-856, 2010.

77. Sato M, Tateishi R, Yasunaga H, et al: Mortality and morbidity of hepatectomy, radiofrequency ablation, and embolization for hepatocellular carcinoma: a national survey of 54,145 patients. J Gastroenterol 47: 1125-1133, 2012.

78. Ray K: Liver cancer: The promise of new approaches in the management of hepatocellular carcinoma - adding to the toolbox? Nat Rev Gastroenterol Hepatol 10: 195, 2013.

79. Qu KZ, Zhang K, Li H, Afdhal NH and Albitar M: Circulating microRNAs as biomarkers for hepatocellular carcinoma. J Clin Gastroenterol 45: 355-360, 2011.

80. Chen X, Ba Y, Ma L, et al: Characterization of microRNAs in serum: a novel class of biomarkers for diagnosis of cancer and other diseases. Cell Res 18: 997-1006, 2008.

81. Ji F, Yang B, Peng X, Ding H, You H and Tien P: Circulating microRNAs in hepatitis B virus-infected patients. J Viral Hepat 18: e242-e251, 2011

82. Mitchell PS, Parkin RK, Kroh EM, et al: Circulating microRNAs as stable blood-based markers for cancer detection. Proc Natl Acad Sci USA 105: 10513-10518, 2008.

83. Li LM, Hu ZB, Zhou ZX, et al: Serum microRNA profiles serve as novel biomarkers for HBV infection and diagnosis of HBV-positive hepatocarcinoma. Cancer Res 70: 9798-9807, 2010.

84. Zhou J, Yu L, Gao X, et al: Plasma microRNA panel to diagnose hepatitis B virus-related hepatocellular carcinoma. J Clin Oncol 29: 4781-4788, 2011.

85. Niu D, Feng $\mathrm{H}$ and Chen WN: Proteomic analysis of HBV-associated HCC: insights on mechanisms of disease onset and biomarker discovery. J Proteomics 73: 1283-1290, 2010.

86. Aguirre-Gamboa R and Trevino V: SurvMicro: assessment of miRNA-based prognostic signatures for cancer clinical outcomes by multivariate survival analysis. Bioinformatics 30 : 1630-1632, 2014.

87. Zhu HT, Dong QZ, Sheng YY, et al: MicroRNA-29a-5p is a novel predictor for early recurrence of hepatitis B virus-related hepatocellular carcinoma after surgical resection. PLoS One 7: e52393, 2012

88. Hoshida Y, Villanueva A, Kobayashi M, et al: Gene expression in fixed tissues and outcome in hepatocellular carcinoma. N Engl J Med 359: 1995-2004, 2008. 
89. Sherman M: Recurrence of hepatocellular carcinoma. N Engl J Med 359: 2045-2047, 2008.

90. Tomimaru Y, Eguchi H, Nagano H, et al: MicroRNA-21 induces resistance to the anti-tumour effect of interferon- $\alpha / 5$-fluorouracil in hepatocellular carcinoma cells. Br J Cancer 103: 1617-1626, 2010.

91. Pineau P, Volinia S, McJunkin K, et al: miR-221 overexpression contributes to liver tumorigenesis. Proc Natl Acad Sci USA 107: 264-269, 2010

92. Xu Y, Xia F, Ma L, et al: MicroRNA-122 sensitizes HCC cancer cells to adriamycin and vincristine through modulating expression of MDR and inducing cell cycle arrest. Cancer Lett 310: 160-169, 2011.

93. Ma K, He Y, Zhang H, et al: DNA methylation-regulated miR-193a-3p dictates resistance of hepatocellular carcinoma to 5-fluorouracil via repression of SRSF2 expression. J Biol Chem 287: 5639-5649, 2012.

94. Tomokuni A, Eguchi H, Tomimaru Y, et al: miR-146a suppresses the sensitivity to interferon- $\alpha$ in hepatocellular carcinoma cells. Biochem Biophys Res Commun 414: 675-680, 2011.

95. Weidhaas JB, Babar I, Nallur SM, et al: MicroRNAs as potential agents to alter resistance to cytotoxic anticancer therapy. Cancer Res 67: 11111-11116, 2007.

96. Mutharasan RK, Nagpal V, Ichikawa $\mathrm{Y}$ and Ardehali $\mathrm{H}$ : microRNA-210 is upregulated in hypoxic cardiomyocytes through Akt- and p53-dependent pathways and exerts cytoprotective effects. Am J Physiol Heart Circ Physiol 301: H1519-1530, 2011.

97. Xie Q, Lin T, Zhang Y, Zheng J and Bonanno JA: Molecular cloning and characterization of a human AIF-like gene with ability to induce apoptosis. J Biol Chem 280: 19673-19681, 2005.

98. Kumar MS, Erkeland SJ, Pester RE, et al: Suppression of non-small cell lung tumor development by the let-7 microRNA family. Proc Natl Acad Sci USA 105: 3903-3908, 2008.

99. Choi WY, Giraldez AJ and Schier AF: Target protectors reveal dampening and balancing of Nodal agonist and antagonist by miR-430. Science 318: 271-274, 2007.

100. Hatakeyama H, Murata M, Sato Y, et al: The systemic administration of an anti-miRNA oligonucleotide encapsulated $\mathrm{pH}$-sensitive liposome results in reduced level of hepatic microRNA-122 in mice. J Controlled Release 173: 43-50, 2014.

101. El Tayebi HM, Hosny KA, Esmat G, Breuhahn K and Abdelaziz AI: miR-615-5p is restrictedly expressed in cirrhotic and cancerous liver tissues and its overexpression alleviates the tumorigenic effects in hepatocellular carcinoma. FEBS Lett 586: 3309-3316, 2012.

102. Fornari F, Milazzo M, Chieco P, et al: In hepatocellular carcinoma miR-519d is up-regulated by p53 and DNA hypomethylation and targets CDKN1A/p21, PTEN, AKT3 and TIMP2. J Pathol 227: 275-285, 2012.

103. Jiang X, Xiang G, Wang Y, et al: MicroRNA-590-5p regulates proliferation and invasion in human hepatocellular carcinoma cells by targeting TGF- $\beta$ RII. Mol Cells 33: 545-551, 2012.

104. Liu WH, Yeh SH, Lu CC, et al: MicroRNA-18a prevents estrogen receptor-alpha expression, promoting proliferation of hepatocellular carcinoma cells. Gastroenterology 136: 683-693, 2009.

105. Notarbartolo M, Giannitrapani L, Vivona N, et al: Frequent alteration of the Yin Yang 1/Raf-1 kinase inhibitory protein ratio in hepatocellular carcinoma. OMOICS 15: 267-272, 2011.

106. Santhekadur PK, Das SK, Gredler R, et al: Multifunction protein staphylococcal nuclease domain containing 1 (SND1) promotes tumor angiogenesis in human hepatocellular carcinoma through novel pathway that involves nuclear factor $\kappa \mathrm{B}$ and miR-221. J Biol Chem 287: 13952-13958, 2012.

107. Yang W, Sun T, Cao J, Liu F, Tian Y and Zhu W: Downregulation of miR-210 expression inhibits proliferation, induces apoptosis and enhances radiosensitivity in hypoxic human hepatoma cells in vitro. Exp Cell Res 318: 944-954, 2012

108. Zhang Y, Wei W, Cheng N, et al: Hepatitis C virus-induced up-regulation of microRNA-155 promotes hepatocarcinogenesis by activating Wnt signaling. Hepatology 56: 1631-1640, 2012.

109. Au SL, Wong CC, Lee JM, et al: Enhancer of zeste homolog 2 epigenetically silences multiple tumor suppressor microRNAs to promote liver cancer metastasis. Hepatology 56: 622-631, 2012

110. Buurman R, Gurlevik E, Schaffer V, et al: Histone deacetylases activate hepatocyte growth factor signaling by repressing microRNA-449 in hepatocellular carcinoma cells. Gastroenterol 143: 811-820, 2012.

111. Di Fazio P, Montalbano R, Neureiter D, et al: Downregulation of HMGA2 by the pan-deacetylase inhibitor panobinostat is dependent on hsa-let-7b expression in liver cancer cell lines. Exp Cell Res 318: 1832-1843, 2012.
112. Huang N, Lin J, Ruan J, et al: MiR-219-5p inhibits hepatocellular carcinoma cell proliferation by targeting glypican-3. FEBS Lett 586: 884-891, 2012.

113. Lang Q and Ling C: MiR-124 suppresses cell proliferation in hepatocellular carcinoma by targeting PIK3CA. Biochem Biophys Res Commun 426: 247-252, 2012.

114. Li D, Yang P, Li H, et al: MicroRNA-1 inhibits proliferation of hepatocarcinoma cells by targeting endothelin-1. Life Sci 91: 440-447, 2012

115. Shah YM, Morimura K, Yang Q, Tanabe T, Takagi M and Gonzalez FJ: Peroxisome proliferator-activated receptor alpha regulates a microRNA-mediated signaling cascade responsible for hepatocellular proliferation. Mol Cell Biol 27: 4238-4247, 2007

116. Tsang WP and Kwok TT: Let-7a microRNA suppresses therapeutics-induced cancer cell death by targeting caspase-3. Apoptosis 13: 1215-1222, 2008

117. Wang Z, Lin S, Li JJ, et al: MYC protein inhibits transcription of the microRNA cluster MC-let-7a-1 let-7d via noncanonical E-box. J Biol Chem 286: 39703-39714, 2011

118. Wei W, Wanjun L, Hui S, Dongyue C, Xinjun Y and Jisheng Z: miR-203 inhibits proliferation of HCC cells by targeting survivin. Cell Biochem Funct 31: 82-85, 2013.

119. Wong QW, Lung RW,Law PT, et al: MicroRNA-223 is commonly repressed in hepatocellular carcinoma and potentiates expression of Stathmin1. Gastroenterology 135: 257-269, 2008.

120. Yuan JH, Yang F, Chen BF, et al: The histone deacetylase 4/SP1/microrna-200a regulatory network contributes to aberrant histone acetylation in hepatocellular carcinoma. Hepatology 54: 2025-2035, 2011.

121. Zheng Y, Yin L, Chen H, et al: miR-376a suppresses proliferation and induces apoptosis in hepatocellular carcinoma. FEBS Lett 586: 2396-2403, 2012.

122. Zhu XM, Wu LJ, Xu J, Yang R and Wu FS: Let-7c microRNA expression and clinical significance in hepatocellular carcinoma. J Int Med Res 39: 2323-2329, 2011.

123. Wang Y, Lee AT, Ma JZ, et al: Profiling microRNA expression in hepatocellular carcinoma reveals microRNA-224 up-regulation and apoptosis inhibitor-5 as a microRNA-224-specific target. J Biol Chem 283: 13205-13215, 2008.

124. Wang Y, Toh HC, Chow P, et al: MicroRNA-224 is up-regulated in hepatocellular carcinoma through epigenetic mechanisms. FASEB J 26: 3032-3041, 2012.

125. Alpini G, Glaser SS, Zhang JP, et al: Regulation of placenta growth factor by microRNA-125b in hepatocellular cancer. J Hepatol 55: 1339-1345, 2011.

126. Fan DN, Tsang FH, Tam AH, et al: Histone lysine methyltransferase, suppressor of variegation 3-9 homolog 1, promotes hepatocellular carcinoma progression and is negatively regulated by microRNA-125b. Hepatology 57: 637-647, 2013.

127. Ji J, Zhao L, Budhu A, et al: Let-7g targets collagen type I alpha2 and inhibits cell migration in hepatocellular carcinoma. J Hepatol 52: 690-697, 2010.

128. Lan FF, Wang H, Chen YC, et al: Hsa-let-7g inhibits proliferation of hepatocellular carcinoma cells by downregulation of c-Myc and upregulation of p16 (INK4A). Int J cancer 128: 319-331, 2011.

129. Lin CJ, Gong HY, Tseng HC, Wang WL and Wu JL: miR-122 targets an anti-apoptotic gene, Bcl-w, in human hepatocellular carcinoma cell lines. Biochem Biophys Res Commun 375: 315-320, 2008.

130. Reddi HV, Madde P, Milosevic D, et al: The putative PAX8/PPAR $\gamma$ fusion oncoprotein exhibits partial tumor suppressor activity through up-regulation of micro-RNA-122 and dominant-negative PPAR $\gamma$ activity. Genes Cancer 2: 46-55, 2011

131. Su H, Yang JR, Xu T, et al: MicroRNA-101, down-regulated in hepatocellular carcinoma, promotes apoptosis and suppresses tumorigenicity. Cancer Res 69: 1135-1142, 2009.

132. Tsai WC, Hsu PW, Lai TC, et al: MicroRNA-122, a tumor suppressor microRNA that regulates intrahepatic metastasis of hepatocellular carcinoma. Hepatology 49: 1571-1582, 2009.

133. Xu J, Zhu X, Wu L, et al: MicroRNA-122 suppresses cell proliferation and induces cell apoptosis in hepatocellular carcinoma by directly targeting Wnt/ $\beta$-catenin pathway. Liver Int 32: $752-760,2012$.

134. Xu T, Zhu Y, Xiong Y, Ge YY, Yun JP and Zhuang SM: MicroRNA-195 suppresses tumorigenicity and regulates G1/S transition of human hepatocellular carcinoma cells. Hepatology 50: 113-121, 2009. 
135. Yang X, Yu J, Yin J, Xiang Q, Tang H and Lei X: MiR-195 regulates cell apoptosis of human hepatocellular carcinoma cells by targeting LATS2. Pharmazie 67: 645-651, 2012.

136. Zhang Y, Guo X, Xiong L, et al: MicroRNA-101 suppresses SOX9-dependent tumorigenicity and promotes favorable prognosis of human hepatocellular carcinoma. FEBS Lett 586: 4362-4370, 2012.

137. Zhao A, Zeng Q, Xie X, et al: MicroRNA-125b induces cancer cell apoptosis through suppression of Bcl-2 expression. J Genet Genomics 39: 29-35, 2012.

138. Wang W, Zhao LJ, Tan YX, Ren H and Qi ZT: MiR-138 induces cell cycle arrest by targeting cyclin D3 in hepatocellular carcinoma. Carcinogenesis 33: 1113-1120, 2012.

139. Wang X, Wang J, Ma H, Zhang J and Zhou X: Downregulation of miR-195 correlates with lymph node metastasis and poor prognosis in colorectal cancer. Med Oncol 29: 919-927, 2012.

140. Wu N, Liu X, Xu X, et al: MicroRNA-373, a new regulator of protein phosphatase 6 , functions as an oncogene in hepatocellular carcinoma. FEBS J 278: 2044-2054, 2011.

141. Odar K, Boštjančič E, Gale N, Glavač D and Zidar N: Differential expression of microRNAs miR-21, miR-31, miR-203, miR-125a-5p and $\mathrm{miR}-125 \mathrm{~b}$ and proteins PTEN and $\mathrm{p} 63$ in verrucous carcinoma of the head and neck. Histopathology 61: 257-265, 2012.

142. Fan Q, He M, Deng X, et al: Derepression of c-Fos caused by microRNA-139 down-regulation contributes to the metastasis of human hepatocellular carcinoma. Cell Biochem Funct 31: 319-324, 2013.

143. Wong CC, Wong CM, Tung EK, et al: The microRNA miR-139 suppresses metastasis and progression of hepatocellular carcinoma by down-regulating Rho-kinase 2 . Gastroenterology 140: 322-331, 2011.

144. Wang X, Chen J, Li F, et al: miR-214 inhibits cell growth in hepatocellular carcinoma through suppression of $\beta$-catenin. Biochem Biophys Res Commun 428: 525-531, 2012.

145. Xia H, Ooi LL and Hui KM: miR-214 targets $\beta$-catenin pathway to suppress invasion, stem-like traits and recurrence of human hepatocellular carcinoma. PLoS One 7: e44206, 2012.

146. Fang Y, Xue JL, Shen Q, Chen J and Tian L: MicroRNA-7 inhibits tumor growth and metastasis by targeting the phosphoinositide 3-kinase/Akt pathway in hepatocellular carcinoma. Hepatology 55: 1852-1862, 2012.
147. Yang $\mathrm{P}$, Li QJ, Feng Y, et al: TGF- $\beta$-miR-34a-CCL22 signaling-induced Treg cell recruitment promotes venous metastases of HBV-positive hepatocellular carcinoma. Cancer Cell 22: 291-303, 2012

148. Jiang C, Pecha J, Hoshino I, Ankrapp D and Xiao H: TIP30 mutant derived from hepatocellular carcinoma specimens promotes growth of HepG2 cells through up-regulation of N-cadherin. Cancer Res 67: 3574-3582, 2007.

149. Tian Q, Liang L, Ding J, et al: MicroRNA-550a acts as a pro-metastatic gene and directly targets cytoplasmic polyadenylation element-binding protein 4 in hepatocellular carcinoma. PLoS One 7: e48958, 2012.

150. Zhou P, Jiang W, Wu L, Chang R, Wu K and Wang Z: miR-301a is a candidate oncogene that targets the homeobox gene Gax in human hepatocellular carcinoma. Dig Dis Sci 57: 1171-1180, 2012.

151. Zhu Q, Wang Z, Hu Y, et al: miR-21 promotes migration and invasion by the miR-21-PDCD4-AP-1 feedback loop in human hepatocellular carcinoma. Oncol Rep 27: 1660-1668, 2012.

152. Li QJ, Zhou L, Yang F, et al: MicroRNA-10b promotes migration and invasion through CADM1 in human hepatocellular carcinoma cells. Tumour Biol 33: 1455-1465, 2012.

153. Liu S, Guo W, Shi J, et al: MicroRNA-135a contributes to the development of portal vein tumor thrombus by promoting metastasis in hepatocellular carcinoma. J Hepatol 56: 389-396, 2012.

154. Long MJ, Wu FX, Li P, Liu M, Li X and Tang H: MicroRNA-10a targets CHL1 and promotes cell growth, migration and invasion in human cervical cancer cells. Cancer Lett 324: 186-196, 2012.

155. Wang B, Hsu SH, Majumder S, et al: TGFbeta-mediated upregulation of hepatic miR-181b promotes hepatocarcinogenesis by targeting TIMP3. Oncogene 29: 1787-1797, 2010.

156. Wang J, Li J, Shen J, Wang C, Yang L and Zhang X: MicroRNA-182 downregulates metastasis suppressor 1 and contributes to metastasis of hepatocellular carcinoma. BMC Cancer 12: 227, 2012.

157. Zhang X, Liu S, Hu T, Liu S, He Y and Sun S: Up-regulated microRNA-143 transcribed by nuclear factor kappa B enhances hepatocarcinoma metastasis by repressing fibronectin expression. Hepatology 50: 490-499, 2009. 